\title{
High-resolution interactive modelling of the mountain glacier-atmosphere interface: an application over the Karakoram
}

\author{
E. Collier ${ }^{1,2}$, T. Mölg 2 , F. Maussion ${ }^{2}$, D. Scherer ${ }^{2}$, C. Mayer ${ }^{3}$, and A. B. G. Bush ${ }^{1}$ \\ ${ }^{1}$ Department of Earth \& Atmospheric Sciences, University of Alberta, Edmonton, Canada \\ ${ }^{2}$ Chair of Climatology, Technische Universität Berlin, Berlin, Germany \\ ${ }^{3}$ Commission for Geodesy and Glaciology, Bavarian Academy of Sciences and Humanities, Munich, Germany \\ Correspondence to: E. Collier (eec@ualberta.ca)
}

Received: 12 November 2012 - Published in The Cryosphere Discuss.: 4 January 2013

Revised: 9 April 2013 - Accepted: 13 April 2013 - Published: 6 May 2013

\begin{abstract}
The traditional approach to simulations of alpine glacier mass balance (MB) has been one-way, or offline, thus precluding feedbacks from changing glacier surface conditions on the atmospheric forcing. In addition, alpine glaciers have been only simply, if at all, represented in atmospheric models to date. Here, we extend a recently presented, novel technique for simulating glacier-atmosphere interactions without the need for statistical downscaling, through the use of a coupled high-resolution mesoscale atmospheric and physically-based climatic mass balance (CMB) modelling system that includes glacier CMB feedbacks to the atmosphere. We compare the model results over the Karakoram region of the northwestern Himalaya with remote sensing data for the ablation season of 2004 as well as with in situ glaciological and meteorological measurements from the Baltoro glacier. We find that interactive coupling has a localized but appreciable impact on the near-surface meteorological forcing data and that incorporation of CMB processes improves the simulation of variables such as land surface temperature and snow albedo. Furthermore, including feedbacks from the glacier model has a non-negligible effect on simulated $\mathrm{CMB}$, reducing modelled ablation, on average, by $0.1 \mathrm{~m}$ w.e. $(-6.0 \%)$ to a total of $-1.5 \mathrm{~m}$ w.e. between 25 June-31 August 2004. The interactively coupled model shows promise as a new, multi-scale tool for explicitly resolving atmospheric-CMB processes of mountain glaciers at the basin scale.
\end{abstract}

\section{Introduction}

Spatially-distributed simulations of glacier surface and climatic mass balance (where the latter term denotes surface plus near-subsurface mass balance following; Cogley et al., 2011) require distributed meteorological forcing; however, obtaining these data is complicated both by the spatial and temporal scarcity of in situ observations and by the "scale mismatch" between the spatial scales represented in atmospheric models and those relevant for surface and climatic MB calculations (e.g. Machguth et al., 2009; Mölg and Kaser, 2011). To overcome these issues, forcing data can be obtained by extrapolation from point measurements by automated weather stations, where available, or interpolation from climate reanalyses and atmospheric model output, using surface- and free-air lapse rates. Surface lapse rates exhibit significant spatial and temporal variability, however, leading to uncertainty in temperature downscaling from altitude changes (Marshall et al., 2007; Gardner et al., 2009; Petersen and Pellicciotti, 2011). In addition, the assumption of linear lapse rates over glacier surfaces may be inappropriate (Petersen and Pellicciotti, 2011) and may under-predict nearsurface temperature over debris-covered regions (Reid et al., 2012). Finally, additional corrections are often required for the poor representation of the strength and spatial variability of processes relevant to mass balance, such as orographic precipitation, in coarse spatial-resolution atmospheric models (e.g. Paul and Kotlarski, 2010; Radić and Hock, 2011).

Dynamical downscaling has been used to address the issue of spatial resolution in the most recent studies to produce climate data at horizontal resolutions of $\sim 18 \mathrm{~km}$ 
(Machguth et al., 2009; Kotlarski et al., 2010a,b; Paul and Kotlarski, 2010), $\sim 11 \mathrm{~km}$ (Van Pelt et al., 2012) and $\sim 1-$ $3 \mathrm{~km}$ grid spacings (Mölg and Kaser, 2011; Mölg et al., 2012a,b) as forcing for distributed alpine glacier surface- and climatic-mass-balance calculations. This approach provides high spatial- and high temporal-resolution atmospheric fields obtained from a physical model, and the increased resolution allows for improved representation of features such as complex topography and orographic precipitation (e.g. Maussion et al., 2011). However, most of these studies required statistical corrections to link mesoscale circulation patterns and meteorological fields simulated by regional atmospheric models to local conditions on the glacier surface. Mölg and Kaser (2011) first showed that, at sufficiently high spatial resolution $(\sim 1 \mathrm{~km})$, a regional atmospheric model could be used to force explicit distributed simulations of glacier CMB without statistical corrections at the glacier-atmosphere interface. This approach has since been applied successfully in multiple locations for small glaciers (Mölg and Kaser, 2011; Mölg et al., 2012a,b).

Traditional approaches to simulations of surface and climatic mass balance, including those discussed above, have been one-way, or offline, in which meteorological fields are passed to the CMB model but changing surface boundary conditions due to $\mathrm{CMB}$ processes are not fed back into the atmospheric model. Interactively or two-way coupled atmospheric and ice-sheet simulations with simple treatments of ablation have been performed to estimate the paleoclimate and future climate behaviours of the Laurentide and Greenland ice sheets, respectively, with significant alterations to atmospheric circulation, temperature and precipitation resulting from ice sheet evolution (Ridley et al., 2005; Pritchard et al., 2008). Although an initial effort has been made to include "interactive" alpine glaciers in a regional atmospheric model with the subgrid-scale parameterization of Kotlarski et al. (2010b), the influence of two-way coupling on the atmospheric forcing and explicitly simulated surface and climatic mass balance has yet to be assessed for alpine glaciers.

Here, we build on a new, unified and explicit approach to resolving the glacier-atmosphere interface without statistical downscaling (Mölg and Kaser, 2011), through the use of an interactively coupled high-resolution mesoscale atmospheric and physically based CMB modelling system. By allowing changes in glacier surface conditions to feed back on the atmospheric drivers, the model provides a consistent calculation of surface energy and mass fluxes. For the initial application of the coupled model, we simulate the Karakoram region of the northwestern Himalaya (Fig. 1), which is estimated to contain anywhere from $\sim 1250-4000 \mathrm{~km}^{3}$ of ice, covering an area of $\sim 18000 \mathrm{~km}^{2}$ (Bolch et al., 2012). Due to its extensive glaciation, this region presents a high potential influence on atmospheric simulations resulting from the inclusion of feedbacks from alpine glaciers. In addition, Yao (2007) estimates that more than half of the glaciated area is contained in the 15 largest glaciers, thus optimizing the Karakoram

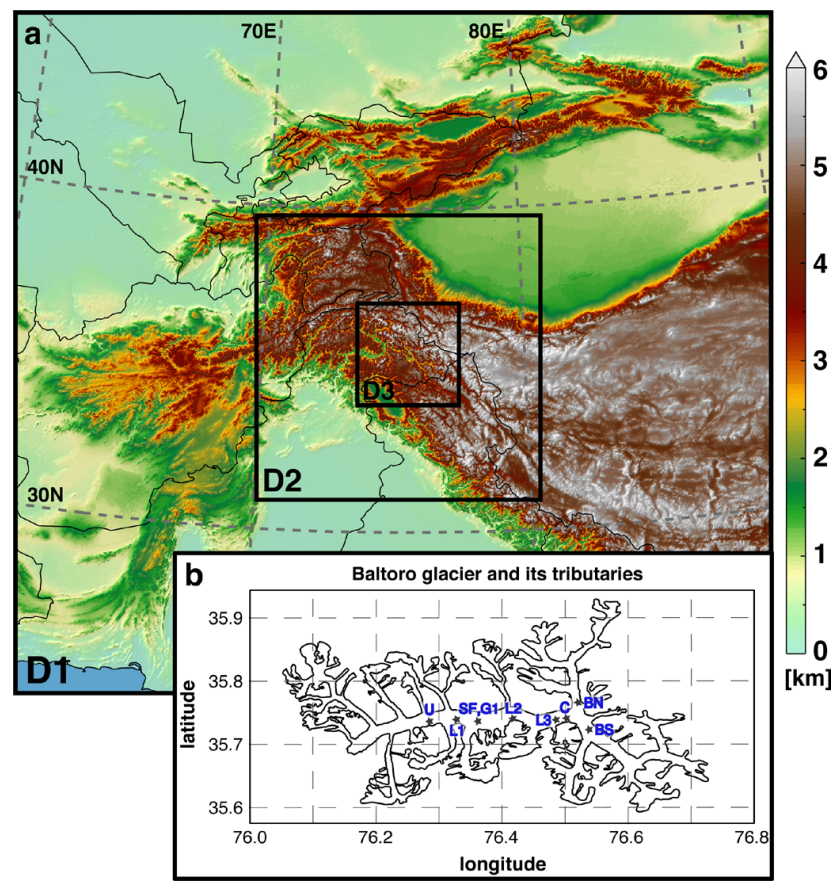

Fig. 1. (a) WRF atmospheric model domains, configured with horizontal spatial resolutions of 33,11 , and $2.2 \mathrm{~km}$. Terrain elevation from the GTOPO30 dataset is shaded in units of meters. (b) Outline of Baltoro glacier and its tributaries, which are included in WRF D3, with the mean stake locations labeled and denoted by stars.

for representation in a high-resolution atmospheric model, where the smallest practical grid spacing is on the order of a few kilometers.

The Karakoram is also of interest due to recent evidence of stable or positive mass balances (e.g. Hewitt, 2005; Scherler et al., 2011; Gardelle et al., 2012; Kääb et al., 2012), which contrasts with the general trend of mass loss exhibited by glaciers elsewhere in the Himalaya (Cogley, 2011). However, definitive statements about the mass balance of Karakoram glaciers have been hampered by a dearth of both in situ measurements and information on ice thickness changes. The latter limitation has been partially addressed by recent geodetic studies (Gardelle et al., 2012; Kääb et al., 2012) that support reduced mass loss or even a positive mass balance anomaly in the early 21 st century but emphasize the spatial and temporal heterogeneity of recent glacier behaviour. In addition, explicit, physically based, spatially distributed numerical modelling has the potential to clarify the dynamics occurring in this region.

In this study, we first evaluate the regional and the local performance, respectively, of the coupled model against available measurements, by comparing the former with surface albedo and temperature over all glacier surfaces and the latter with meteorological fields and ablation on the Baltoro glacier. We then aim to (1) explore the importance of energy and mass exchanges between the glacier surface and 
boundary layer on the atmospheric forcing, and (2) assess the ultimate influence of interactive coupling on simulations of glacier mass balance. A final goal of this work is to improve the representation of alpine glaciers in mesoscale atmospheric models by introducing additional, relevant physical processes.

\section{Methodology}

The coupled modelling system (hereafter "WRF-CMB") consists of two components: the advanced research version of the nonhydrostatic and fully compressible Weather Research and Forecasting (WRF) mesoscale atmospheric model version 3.4 (Skamarock and Klemp, 2008, Sect. 2.1) and the process-based surface-energy and CMB model of Mölg et al. (2008, 2009, 2012a, Sect. 2.2). The CMB model has been incorporated into the WRF source code as an additional physics option, and, thus, the user may select via runtime ("namelist") options whether the CMB simulation is offline (conventional one-way forcing, with feedbacks only from WRF's land surface model) or interactive (feedback from CMB model to WRF over glaciated grid cells; Sect. 2.3). We performed two simulations, one interactive (INT) and one offline (OFF), for the months of June-August 2004, to coincide with a limited number of glaciological and meteorological measurements from the Baltoro glacier available for evaluation (Sect. 2.4), with the period of 1-25 June discarded as model spin-up time. Here we use the term interactive to denote surface-atmosphere exchanges through heat, moisture and momentum fluxes only and not through topographic feedbacks, as glacier geometry is held constant over our brief simulation. As a first approximation, we focused on the meteorologically driven fluctuations of mass balance and neglected the influence of debris cover.

\subsection{Mesoscale atmospheric model}

For these simulations, WRF was configured with three nested domains of 33,11 and $2.2 \mathrm{~km}$ spatial resolution, centered over the northwestern Himalaya (D1-3; Fig. 1). By increasing the spatial resolution over the region of interest, the use of multiple grid nesting improves the representation of complex terrain and associated processes such as orographic precipitation, and has been found to increase the simulation skill of WRF for mountain summit conditions (Mölg and Kaser, 2011). Model physics and other settings were selected following the recommendations of the National Center for Atmospheric Research (NCAR) for regional climate simulations with WRF (Table 1; outlined in WRF ARW user's guide). Note that no cumulus parameterization was employed in the highest-resolution, convection-permitting model domain, WRF D3 (e.g. Molinari and Dudek, 1992; Weisman et al., 1997). The range of terrain elevation represented in this domain at $2.2 \mathrm{~km}$ resolution is 916 to $7442 \mathrm{~m}$ a.s.l.,
Table 1. WRF configuration.

\begin{tabular}{ll}
\hline Model domains & \\
\hline Horizontal grid spacing & $33,11,2.2 \mathrm{~km}$ (domains 1-3) \\
Time step & $60,20,4 \mathrm{~s}$ \\
Vertical levels & 40 \\
Height of lowest model level & $\sim 20 \mathrm{~m}$ \\
Model top pressure & $25 \mathrm{hPa}$ \\
\hline Model physics & \\
\hline Radiation & CAM \\
Microphysics & Thompson \\
Cumulus & Kain-Fritsch (none in D3) \\
Atmospheric boundary layer & Yonsei University \\
Surface layer & Monin-Obukhov (revised MM5) \\
Land surface & Noah version 3.1 \\
\hline Dynamics & \\
\hline Top boundary condition & w-Rayleigh damping \\
Horizontal advection & Explicit 6th order coeff: \\
& $0.12,0.12,0.36$ \\
\hline Lateral boundaries & \\
\hline Specified boundary width & 10 grid points \\
Relaxation exponent & 0.33 \\
Forcing & ERA Interim, $0.75^{\circ} \times 0.75^{\circ}$ \\
& updated 6-hourly \\
\hline
\end{tabular}

which encompasses the most heavily glaciated altitudes in the Karakoram $(\sim 2700-7200 \mathrm{~m}$, as shown in Fig. S2 of Bolch et al. (2012), with the mean basin-wide glacier elevation located at $5326 \mathrm{~m}$ ).

In this study, WRF was coupled with the Noah land surface model (LSM; Chen and Dudhia, 2001). The land-ice mask was updated using glacier outlines for the Karakoram region based on the glacier inventory of China (Shi et al., 2009) as well as inventories generated by ICIMOD (2007) and GlobGlacier (Frey et al., 2012). Other modifications made to glaciated grid cells included assigning (1) zero vegetation cover, (2) maximum and minimum albedo values consistent with the parameterization in the CMB model (Sect. 2.2), and (3) a soil moisture availability of 1.0 (from an original value of 0.95). The conventional bulk computation of the latent heat flux in the WRF surface module is multiplied by the last parameter; therefore, this change was made for consistency with the CMB model.

The atmospheric model was forced with ERA-Interim data at $0.75^{\circ} \times 0.75^{\circ}$ spatial-resolution and 6-hourly temporalresolution, as provided by the European Centre for MediumRange Weather Forecasts (ECMWF; Dee et al., 2011). In the ERA-Interim reanalysis, snow depth is arbitrarily set to $10 \mathrm{~m}$ in the analysis for grid cells with greater than $50 \%$ glacier coverage (Paul Berrisford, personal communication, 2012), which results in unphysical snow depths over the Karakoram. We therefore obtained the initial snow condition from the microwave-derived Global EASE-Grid 8-day Blended 
Table 2. MB model configuration.

\begin{tabular}{ll}
\hline Vertical levels (14) & $0,0.1,0.2,0.3,0.4,0.5,0.8$, \\
& $1,1.4,2,3,5,7,9 \mathrm{~m}$ \\
Fresh snow density & $250 \mathrm{~kg} \mathrm{~m}^{-2}$ \\
Ice density & $900 \mathrm{~kg} \mathrm{~m}^{-2}$ \\
& \\
\hline Albedo scheme parameters & Mölg et al. (2012a) \\
\hline & \\
Ice albedo & 0.30 \\
Firn albedo & 0.55 \\
Fresh snow albedo & 0.85 \\
Time scale & 6.0 days \\
Depth scale & $8.0 \mathrm{~cm}$ \\
\hline
\end{tabular}

SSM/I and MODIS Snow Cover SWE data (Brodzik et al., 2007), assuming a snow density of $300 \mathrm{~kg} \mathrm{~m}^{-2}$ and assigning an initial depth of $2 \mathrm{~m}$ over large glaciers where these data are missing (less than $0.1 \%$ ( 8 in total) of data points in the region spanned by WRF D1).

WRF employs a terrain-following hydrostatic-pressure coordinate in the vertical, defined as eta $(\eta)$ levels (Skamarock and Klemp, 2008). For these simulations, the lowest atmospheric model level was specified at $\eta=0.997585(\sim 20 \mathrm{~m})$ to maintain the validity of the constant-flux assumption in the bulk computation of the turbulent heat fluxes, as the surface mid-layer height (less than $10 \mathrm{~m}$ ) is used in the calculation following the approach of the Noah LSM. We selected the recently revised Monin-Obukhov surface layer (Jiménez et al., 2012), which was found to improve the simulation of the diurnal amplitudes of near-surface meteorological fields over complex terrain with a horizontal spatial resolution of $2 \mathrm{~km}$. We also used positive-definite explicit 6th order diffusion (Knievel et al., 2007), in order to dampen grid-scale noise in the atmospheric fields and because Mölg and Kaser (2011) found this option improved the simulated magnitude of precipitation at high elevations on Kilimanjaro. For the simulations presented here, we selected the default value of the diffusion coefficient $(0.12)$ for all model domains except D3, for which we used a value of 0.36 . The choice of the diffusion parameter value is uncertain; sensitivity runs revealed that increasing the strength increased simulated precipitation at high elevations, which may be attributable to increased diffusive transport, with the best agreement with the Urdukas AWS data found for the selected value.

\subsection{Surface energy and mass balance model}

The CMB model is described fully by Mölg et al. (2008, 2009) with the most recent updates in Mölg et al. (2012a), but we will review some important features here. The model computes the column specific mass balance from solid precipitation, surface deposition and sublimation, surface and subsurface melt, and refreeze of both meltwater and liquid precipitation. To determine the mass fluxes, the model first solves the surface energy balance equation:

$S \downarrow \cdot(1-\alpha)+L \downarrow+L \uparrow+\mathrm{QS}+\mathrm{QL}+\mathrm{QG}+\mathrm{QPRC}=F_{\mathrm{NET}}$

in which the terms correspond to, from left to right: incoming short-wave radiation, broadband albedo, incoming and outgoing long-wave radiation, turbulent fluxes of sensible and latent heat, ground heat flux and heat flux from precipitation. The ground heat flux, QG, consists of a conductive component (QC) as well as a component due to subsurface penetration of short-wave radiation (QPS). The net flux, $F_{\mathrm{NET}}$, represents the energy available for melt, QM, provided the surface temperature is at the melting point, $T_{\mathrm{M}}=273.15 \mathrm{~K}$.

The model treats both surface and subsurface processes, including surface albedo and roughness evolution based on snow depth and age; snowpack compaction and densification by refreeze; and the influence of penetrating solar radiation, refreeze and conduction on the englacial temperature distribution. The CMB model is forced by air temperature, humidity, wind speed, and air pressure, all of which were taken from the lowest model level $(z=20 \mathrm{~m})$. Note that the diagnostically updated 2 and $10 \mathrm{~m}$ meteorological fields were not used as forcing so as to (1) be consistent with the approach of the Noah LSM (Chen and Dudhia, 2001), and (2) prevent decoupling of the atmosphere and land surface, wherein the lower atmosphere is no longer influenced by surface conditions. The CMB model also takes as input: total precipitation and its frozen fraction; incoming short- and long-wave radiation; and time between snowfall events. Some model parameter values are provided in Table 2 . The initial subsurface temperature was specified through linear interpolation of the input data to the Noah LSM, available at 0.1, 0.4, 1.0, and $2.0 \mathrm{~m}$ depths, and assigning a constant value of $268.6 \mathrm{~K}$ below this level. The lower boundary is specified at $268.6 \mathrm{~K}$ during the simulation, based on measurements taken from a Tibetan glacier (Mölg et al., 2012a). We address uncertainties in the subsurface temperature initialization by including a long (25 day) model spin-up period.

\subsection{Coupling architecture}

For both offline and interactive simulations, the CMB model calculates glacier surface-energy and surface- and nearsurface-mass fluxes among other variables at every time step (e.g. every $4 \mathrm{~s}$ in D3) over glaciated grid cells, while the Noah LSM values are retained over non-glaciated grid cells. The integrated modelling approach permits some advantages in the CMB model's forcing strategy. For example, topographic shading, incoming short- and long-wave radiation, and the fraction of frozen precipitation are now obtained from the atmospheric model's surface, radiation, and microphysics modules, respectively. Another important advantage is that WRF provides high-resolution, dynamically derived, and spatially distributed forcing data without the need for traditional statistical methods, such as those mentioned in 
Table 3. Summary of available ablation stake measurements from the Baltoro glacier.

\begin{tabular}{llll}
\hline $\begin{array}{l}\text { Stake section } \\
\text { (Symbol) [Num. Stakes] }\end{array}$ & $\begin{array}{l}\text { Measurement } \\
\text { period (2004) }\end{array}$ & Mean location & $\begin{array}{l}\text { Mean elevation } \\
\text { (m a.s.1.) }\end{array}$ \\
\hline Urdukas (U) [4] & 2-15 July & $76.285^{\circ} \mathrm{E}, 35.737^{\circ} \mathrm{N}$ & 3993 [WRF: 4202] \\
Longitudinal Sect. 1 (L1) [2] & 3-14 July & $76.328^{\circ} \mathrm{E}, 35.740^{\circ} \mathrm{N}$ & 4120 [WRF: 4201] \\
Stake Farm (SF) [23] & 4-14 July & $76.362^{\circ} \mathrm{E}, 35.737^{\circ} \mathrm{N}$ & 4177 [WRF: 4262] \\
Gore 1 (G1) [4] & 4-13 July & $76.364^{\circ} \mathrm{E}, 35.739^{\circ} \mathrm{N}$ & 4182 [WRF: 4303] \\
Longitudinal Sect. 2 (L2) [4] & 5-12 July & $76.418^{\circ} \mathrm{E}, 35.742^{\circ} \mathrm{N}$ & 4308 [WRF: 4347] \\
Longitudinal Sect. 3 (L3) [2] & 8-11 July & $76.486^{\circ} \mathrm{E}, 35.739^{\circ} \mathrm{N}$ & 4470 [WRF: 4601] \\
Concordia (C) [5] & 8-11 July & $76.502^{\circ} \mathrm{E}, 35.742^{\circ} \mathrm{N}$ & 4537 [WRF: 4622] \\
Baltoro South (BS) [5] & 7-11 July & $76.538^{\circ} \mathrm{E}, 35.724^{\circ} \mathrm{N}$ & 4634 [WRF: 4704] \\
Baltoro North (BN) [4] & 8-11 July & $76.520^{\circ} \mathrm{E}, 35.766^{\circ} \mathrm{N}$ & 4646 [WRF: 4760] \\
\hline
\end{tabular}

Sect. 1. The incorporation of the CMB model for all glacier grid points in the coupled model adds negligible computational expense to WRF simulations.

For interactive simulations, the CMB model updates over glaciated areas in WRF, at every time step: (1) surface heat and moisture fluxes, (2) surface and subsurface (including deep soil) temperature, (3) snow depth, water equivalent and fractional cover, (4) surface albedo and roughness, and (5) surface specific humidity. The inclusion of feedbacks represents a more consistent approach, as it permits the nearsurface forcing variables to be modified by exchanges of mass, momentum and moisture between the glacier and the atmospheric surface layer. In this study, the CMB model output accumulated energy and mass fluxes every hour that were then converted into hourly averages for analysis; these data will be referred to as "hourly".

As indicated at the beginning of Sect. 2, it is not absolutely correct to label the two forcing approaches as "offline" and "interactive" because the atmospheric model currently receives surface feedbacks through the Noah LSM. There have been recent efforts to improve the simulation of snow processes in WRF, such as with the introduction of the NoahMP land surface parameterization (Niu et al., 2011), which, for example, introduces separate vegetation canopy and surface layers and the possibility of multiple vertical layers in the snowpack. However, the simplified treatment of glacier grid cells in the Noah LSM is retained. Thus, by incorporating the $\mathrm{CMB}$ model, we are able to simulate more physical processes relevant for glaciers, such as refreezing of meltwater in the snowpack, englacial melt, and formation of superimposed ice. Other improvements to the treatment of snow and ice physics, compared with the Noah LSM, include introducing multiple layers in the snowpack, increasing the column depth from 2 to $9 \mathrm{~m}$, consideration of snow porosity, and allowing for full snowpack ablation to expose bare ice. The latter point is especially critical, as the Noah LSM imposes minimum snow depth and water equivalent values over land-ice grid cells.

\subsection{Measurements for model evaluation}

In Sect. 3.2, we compare the coupled model results with a limited number of available ablation stake measurements as well as automated weather station (AWS) data that were acquired in summer 2004 on the Baltoro glacier $\left(35^{\circ} 35^{\prime}-\right.$ $35^{\circ} 56^{\prime} \mathrm{N}, 76^{\circ} 04^{\prime}-76^{\circ} 46^{\prime} \mathrm{E}$; Mihalcea et al., 2006). The glacier is approximately $62 \mathrm{~km}$ long, with an average (maximum) width of 2.1 (3.1) km (Mayer et al., 2006). Therefore, in WRF-CMB the Baltoro glacier is represented by at least one grid point in the along-glacier direction and we resolve longitudinal rather than transverse gradients in surface conditions. We use data from 6 sections (SF, U, G1, C, BN, and $\mathrm{BS})$ as well as from longitudinal transects along the glacier (L1, L2 and L3), comprising 53 stakes in total that provide sufficient spatial coverage (cf. Figs. 1b or 4 b) to evaluate both the spatial pattern and the magnitude of ablation in the coupled model applied to the Baltoro glacier. The ablation measurements were taken at different intervals between 115 July 2004; a brief summary of the location and other details of the stake measurements are given in Table 3 (a more detailed description of the data can be found in Mihalcea et al., 2006). While the data represent a brief period, they provide the only available direct ablation measurements in the Karakoram. For the comparison, total simulated surface lowering was interpolated to the mean location of the stake section or transect using inverse distance weighting.

The AWS was situated adjacent to the glacier on a moraine ridge at an elevation of $4022 \mathrm{~m}\left(35^{\circ} 43.684^{\prime} \mathrm{N}\right.$, $\left.76^{\circ} 17.164^{\prime} \mathrm{E}\right)$ and provided hourly mean data after 18 June 2004 (Mihalcea et al., 2006). We compared these data with WRF data from the nearest model grid point (located at an elevation of $4322 \mathrm{~m}$ ), which was also nonglaciated and therefore was more consistent in the land surface type. However, the data therefore do not include direct feedbacks from the CMB model. Note that the assumptions discussed in Sect. 2.1 for snow initialization were not applied over the stake sites on the main glacier area (cf. Fig. 1b).

To supplement these field measurements, we also evaluate in Sect. 3.1 the basin-scale performance of the coupled model 
using MODIS/Aqua (1) MYD10A1 daily snow albedo available at $500 \mathrm{~m}$ resolution, and (2) MYD11A2 eight-day land surface temperature available at $1 \mathrm{~km}$ resolution, with daily data obtained by averaging day- and night-time temperatures where both fields were available and were assigned the highest quality assurance flag for MODIS products. Due to the prevalence of missing data in the snow albedo dataset, we considered only the grid cells with at least $25 \%$ valid observations during the 67 day period for comparison with WRF. Both MODIS datasets were re-projected to the WRF D3 grid before completing the analysis.

\section{Results and discussion}

We first compare our simulated results with remote sensing data (Sect. 3.1) and with meteorological and glaciological measurements from the Baltoro glacier (Sect. 3.2). The role of interactive coupling on the atmospheric forcing data and on simulations of CMB will then be discussed. Results are presented from the finest-resolution atmospheric model domain only, since it provides the most realistic terrain representation.

\subsection{Remote sensing data}

Figure 2 presents a comparison between WRF-CMB and the MODIS/Aqua datasets discussed in Sect. 2.4. The elevational profile of land surface temperature (LST) averaged over the simulation period produced by the CMB model is in good agreement with the MODIS data above $\sim 5200 \mathrm{~m}$ and is an improvement on the Noah LSM values at all resolved elevations (Fig. 2a). The strong divergence of modelled and observed LST below $5200 \mathrm{~m}$ likely results from neglecting debris cover, since its presence allows the glacier surface to be warmed by solar radiation above the melting point. Supraglacial debris extent has also been found to increase with distance down glacier in remote-sensing case studies of the central Karakoram (e.g. Scherler et al., 2011). Specific to the Baltoro glacier and its tributaries, Mayer et al. (2006) found that debris coverage increased to $70-90 \%$ of the glacier area below $5000 \mathrm{~m}$, with $100 \%$ coverage found below the $\mathrm{U}$ site (Fig. 1b). A time-series analysis of LST, averaged only over elevations greater than $5200 \mathrm{~m}$ is presented in Fig. 2c. The CMB model gives an improved performance over the LSM alone, although LST is generally under-predicted, with mean biases of $-1.0,-1.3$, and $-6.1 \mathrm{~K}$ in the INT, OFF, and Noah LSM simulations, respectively. Conversely, snow albedo in WRF-CMB is in good agreement with MODIS below $\sim 5200 \mathrm{~m}$ (Fig. $2 \mathrm{~b}$ ), although simulated values are constrained by the lower bound of $\alpha_{\text {ice }}=0.3$ as snow depth goes to zero and, thus, slightly overestimate the observational values at the lowest elevations. Above $5200 \mathrm{~m}$, WRF-CMB over-predicts snow albedo compared with MODIS. However, it produces values and an
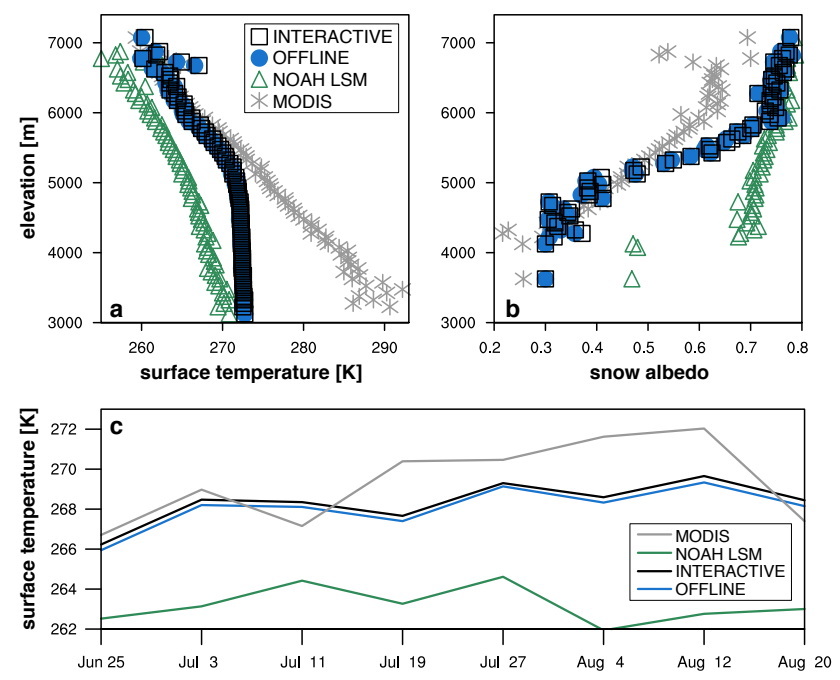

Fig. 2. Comparison between WRF-CMB D3, Noah LSM, and MODIS for land surface temperature, (a) averaged from 25 June28 August 2004, and in $50 \mathrm{~m}$ elevation bins; (c) the mean time series above 5200 m elevation; and for (b) snow albedo, averaged between 25 June-31 August 2004, over glacier grid cells where at least $25 \%$ of the daily times are available.

altitudinal gradient that are in much better agreement with observations than the Noah LSM.

The strong discrepancy between Noah LSM and MODIS data is in part related to the treatment of grid cells defined as glacial ice: the LSM in WRF v3.4 imposes minimum values of snow depth and water equivalent of 0.5 and $0.1 \mathrm{~m}$, respectively, thus preventing the exposure of bare ice or debris and the associated lowering of surface albedo. In addition, the Noah LSM employs a time-decaying snow albedo formulation (based on the scheme of Livneh et al., 2009) and determines surface albedo using fractional snow cover to correct a background snow-free albedo. Although snow albedo is likewise an exponential function of age in the CMB model (following Oerlemans and Knap, 1998), the actual surface albedo also depends on snow depth to account for surface darkening when the snowpack is thin. It is clear from Fig. 2 that this formulation, in combination with permitting snowfree conditions, gives more realistic values.

The evaluation of modelled albedo is sensitive to the simulated timing of snowfall events for both models, due to the nature of the parameterization schemes, and is limited by the large number of missing data in MODIS. In addition, comparison is hindered by the fact that the MODIS daily albedo product is not a daily-averaged quantity (as the simulated data are) but rather a collection of pixels with the highest quality from that day for which acquisition time is not trivial to retrieve (Stroeve et al., 2006). Finally, the small positive biases in snow albedo below $\sim 4300 \mathrm{~m}$ and the negative biases in LST are both physically consistent with neglecting the influence of debris cover in WRF-CMB, as will be discussed further in Sect. 3.4. 

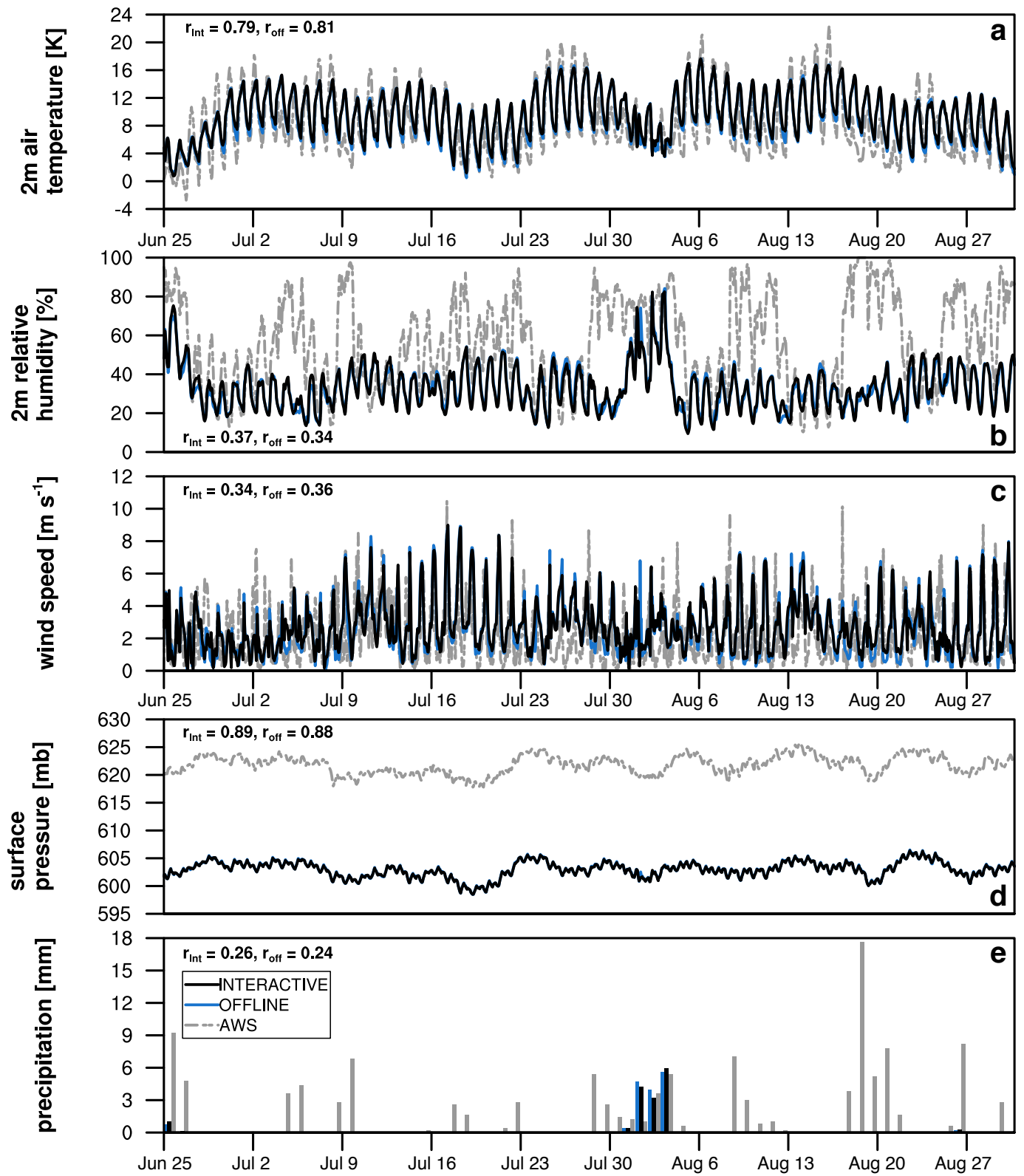

Fig. 3. Hourly (a) air temperature at $2 \mathrm{~m}$, (b) relative humidity at $2 \mathrm{~m}$, (c) wind speed at $10 \mathrm{~m}$, and (d) surface air pressure, as well as (e) daily total precipitation. Solid black (blue) curves display data from the interactive (offline) simulations while the dashed grey curve is the Urdukas AWS station data. Note the difference in elevation of the AWS (4022 ma.s.1.) and the terrain height in the closest WRF grid cell (4322 m).

\subsection{Baltoro glacier}

Figure 3 presents a time series of modelled and observed near-surface meteorological data from the Urdukas AWS that is situated adjacent to the Baltoro glacier. WRF-CMB is skillful in simulating air temperature at $2 \mathrm{~m}$, and its evolution over the study period, including capturing periods of reduced diurnal variability at the beginning and between 30 July and 6 August. However, the good agreement in near-surface temperature despite a difference in real and modelled elevation of $\sim 300 \mathrm{~m}$ (4022 vs. $4322 \mathrm{~m}$ a.s.l., respectively) suggests that there is a positive temperature bias in WRF-CMB at this grid point. The greatest contributing factor is higher incoming short-wave radiation: averaged over the simulation period, the surface in INT receives an additional $112 \mathrm{~W} \mathrm{~m}^{-2}$ more radiation than measured by the AWS (not shown). The discrepancy is most likely due to insufficient simulated cloud cover and humidity (Fig. 3b), with a potential contribution also from the computation of topographic shading at $2.2 \mathrm{~km}$ resolution. Finally, the amplitude of the diurnal temperature 
Table 4. Ablation rates $\left(\mathrm{cm} \mathrm{day}^{-1}\right)$ and debris thickness on the Baltoro glacier.

\begin{tabular}{lcccc}
\hline Site & INT & OFF & $\begin{array}{c}\text { Average } \\
\text { measured (ice) }\end{array}$ & $\begin{array}{c}\text { Mean debris } \\
\text { thickness }(\mathrm{cm})\end{array}$ \\
\hline U & -5.6 & -5.5 & -3.9 & 8.6 \\
L1 & -5.4 & -5.3 & -3.5 & 7.0 \\
SF & -5.2 & -5.1 & -4.3 & 3.8 \\
G1 & -5.2 & -5.1 & -2.9 & 18.0 \\
L2 & -5.1 & -5.1 & -4.8 & 2.5 \\
L3 & -5.0 & -4.9 & -4.3 & 2.0 \\
C & -4.9 & -4.9 & -2.9 & 6.0 \\
BS & -6.4 & -5.6 & -1.8 & 6.8 \\
BN & -7.4 & -7.7 & -1.8 & 7.8 \\
\hline
\end{tabular}

cycle is smaller in WRF-CMB, which may be attributable to differing thermal properties of the real and modelled land surface or to the fact that the AWS sensor was not aspirated.

The magnitude of the near-surface wind speed is also in agreement with the AWS data (Fig. 3c). However, an important discrepancy is the underestimation of precipitation at this particular grid cell in both INT and OFF simulations: the AWS records a total of $122.8 \mathrm{~mm}$ of precipitation between 25 June and 31 August, while INT and OFF simulate 46.9 and $48.4 \mathrm{~mm}$, respectively (Fig. 3e). Missing precipitation events are also reflected as discrepancies in the time series of relative humidity (cf. Fig. 3b, e) and are consistent with an overestimation of incoming short-wave radiation as a result of too little cloud cover. The disagreement in measured and simulated humidity and precipitation may reflect several sources of error, such as in the forcing data at the lateral boundaries. In addition, the spatial resolution of WRF D3 may be insufficiently fine to fully resolve orographic uplift or microscale complex flow features that affect precipitation at the AWS. Furthermore, we do not use a cumulus parameterization in the finest model domain and therefore assume that convection is explicitly resolved. However, previous studies indicate that a grid spacing on the order of $100 \mathrm{~m}$ (Bryan et al., 2003; Petch, 2006) or even $10 \mathrm{~m}$ (Craig and Dörnback, 2008) is needed to capture the dominant length scales of moist cumulus convection. A final potential error source is the difference in the land surface type adjacent to the AWS and model grid cell: the Baltoro glacier is debriscovered at the Urdukas site, while WRF-CMB has a clean snow/ice surface. The differing thermal properties of the adjacent surface area, specifically the limiting of temperature at the melting point in WRF-CMB, may also contribute to differences in localized convection.

WRF-CMB produces 40 to $80 \mathrm{~cm}$ of ablation along the main body of the Baltoro glacier between 1-15 July 2004 (Fig. 4a). Spatial comparison of the two simulations reveals only small differences, generally on the order of a few centimetres, consistent with the short nature of the study period (Fig. 4b). There are slightly positive anomalies at
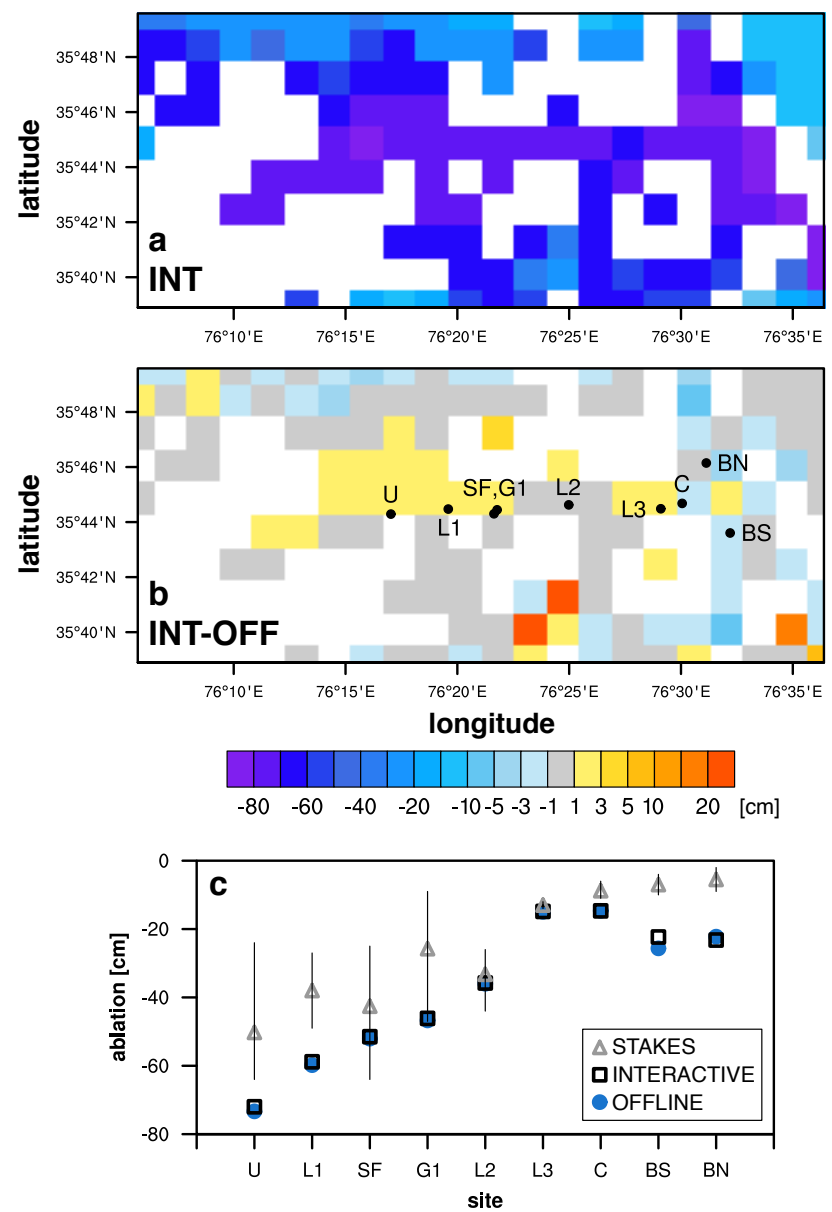

Fig. 4. (a) Total and (b) INT-OFF surface height change between 1-15 July 2004, in the vicinity of the main tongue of the Baltoro glacier. Stake site and transect locations shown in (b), with additional information provided in Table 3. White grid cells correspond to non-glaciated area. (c) Measured mean ablation (triangles) at stake locations, with range of observed values denoted by bars. Simulated INT (OFF) ablation shown by black squares (blue circles).

lower elevations, corresponding to less ablation in INT; conversely, there are negative anomalies at higher elevations, corresponding to more ablation in INT. Total simulated ablation is in order-of-magnitude agreement with measurements (Fig. 4c); however, the model overestimates ablation at all sites, in part because it does not capture four all-phase precipitation events, amounting to $17.6 \mathrm{~mm}$, during the measurement period (cf. Fig. 3e). In comparing daily simulated/measured ablation rates and mean debris thickness $(\mathrm{Ta}-$ ble 4), the rates tend to be in better agreement for sites with thinner mean debris cover (SF, L2, L3, C) and more strongly overestimated by WRF-CMB where supraglacial debris is thicker (U, L1, G1, BN, BS). Although differences between INT and OFF are small, INT is in closer agreement with observations at all but one site (BN, as a result of less simulated 

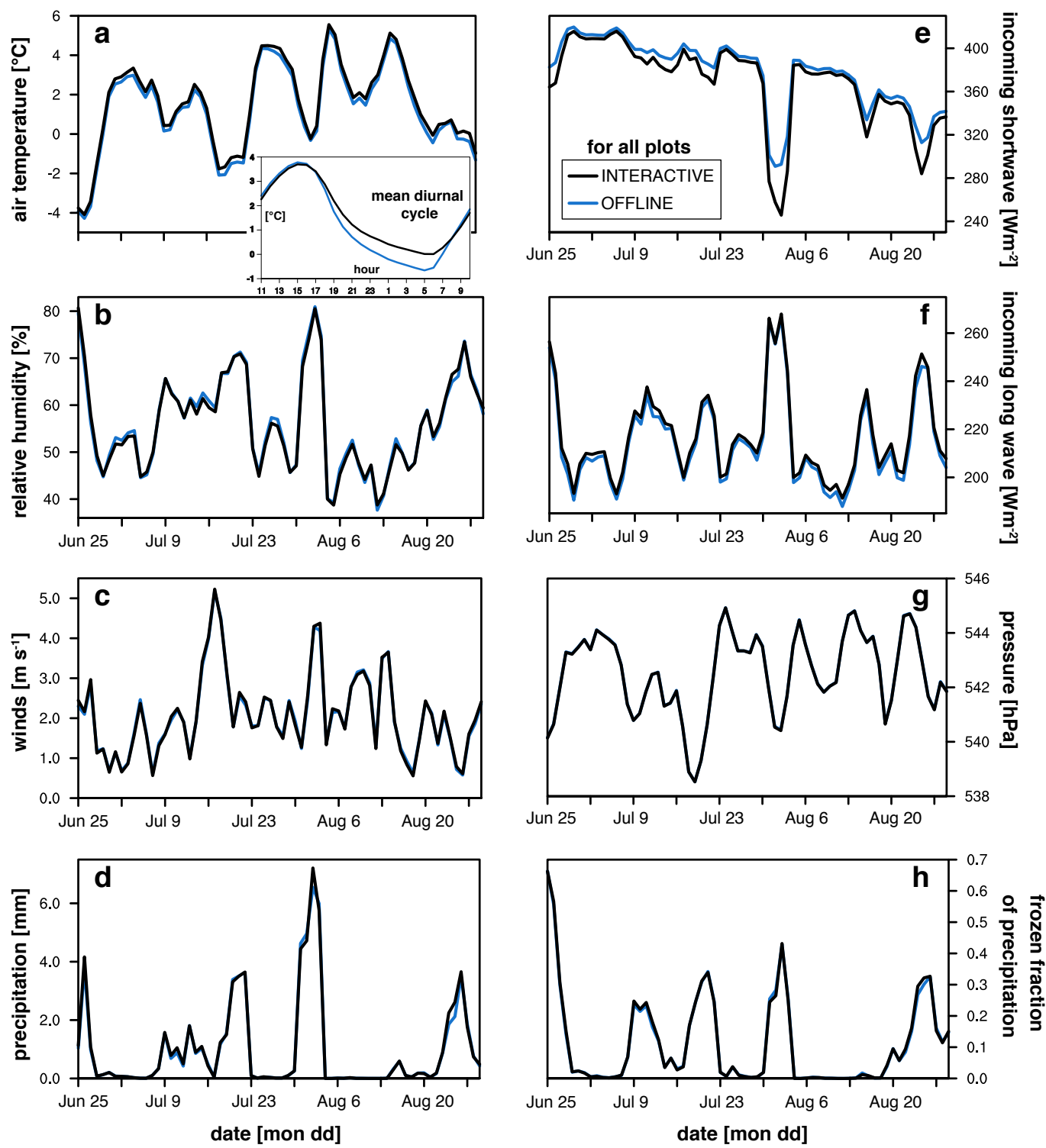

Fig. 5. Daily mean (a) air temperature, (b) relative humidity, (c) wind speed, (d) total precipitation, incoming (e) normal short-wave and (f) downward long-wave radiation at ground surface, $(\mathbf{g})$ air pressure, and (h) frozen fraction of precipitation, area-averaged over all glaciated grid cells. Data for $(\mathbf{a}-\mathbf{c})$, and $(\mathbf{g})$ are taken from the lowest model level $(z=20 \mathrm{~m})$. The subpanel in (a) presents the average diurnal temperature cycle over the simulation period. Black (blue) curves display data from the interactive (offline) simulation.

refreeze than in OFF), with the strongest improvement at BS. The improvement at this site stems from faster complete snow cover removal $(\sim 1$ day earlier in INT), which reduces subsurface penetration of short-wave radiation and, thus, subsurface melt production. Finally, the overestimation of ablation by WRF-CMB tends to diminish as the observation period increases (Fig. 4d), which then suggests that the coupled model as configured in this study may be best suited for "climatological" simulations of glacier mass balance due to its sensitivity to the timing of precipitation.

Mihalcea et al. (2008) performed distributed surfaceenergy sub-debris melt modelling, using the Urdukas AWS data as forcing for the same study period. The authors determined debris extent, thickness and thermal properties from satellite imagery, and considered only the elevation range of 3650-5400 m a.s.l., which gives a corresponding glacier area of $124 \mathrm{~km}^{2}$. Mihalcea et al. (2008) computed $0.058 \mathrm{~km}^{3}$ w.e. of ablation, or a mean surface lowering of $0.47 \mathrm{~m}$ between 1-15 July, which was found to be a slight underestimation (on average, $-0.016 \mathrm{~m}$ ) of the observed ablation rates at the SF site. For comparison, INT and OFF simulate 0.069 and $0.070 \mathrm{~km}^{3}$ w.e. of surface melt, respectively, over an area of $126 \mathrm{~km}^{2}$ that produces an average thickness change of approximately $-0.55 \mathrm{~m}$. The actual CMB calculation in the 
model also includes additional processes, such as snowpack ablation and surface vapour fluxes, that bring the total simulated mass loss to $0.078 \mathrm{~km}^{3}$ w.e. between 1-15 July. We employ the same glacier outline, that of Mayer et al. (2006); however, discrepancies in our estimates may arise from its projection to the WRF D3 grid, differences in removal of tributary glaciers, and the coarser representation of the Baltoro glacier at $2.2 \mathrm{~km}$ spatial resolution (vs. $90 \mathrm{~m}$ in Mihalcea et al., 2008). Despite these and other sources of disagreement, comparing the two estimates gives an approximate measure of the effect of neglecting debris, which is thought to cover $38 \%$ of the Baltoro glacier (Mayer et al., 2006) and $73 \%$ of the altitude range of the main glacier tongue considered in Mihalcea et al. (2008), in our simulations.

\subsection{Influence of interactive coupling}

Figure 5 presents a time series of daily means of the nearsurface WRF meteorological data used as forcing for the $\mathrm{CMB}$ model and provides the context for the fluctuations of surface energy and mass fluxes discussed in this section. Near-surface air temperatures in INT are higher by $0.3{ }^{\circ} \mathrm{C}$ on average than in OFF (Fig. 5a). The difference arises primarily from a reduced amplitude of the diurnal cycle, with higher nocturnal temperatures (Fig. 5a subpanel). INT simulates higher surface temperatures $\left(T_{\text {sfc }}\right)$, as well as higher subsurface temperatures in the top 0.5-1 $\mathrm{m}$ (peak differences are $\sim 0.7^{\circ} \mathrm{C}$, not shown), as a result of stronger downward long-wave radiative forcing (see Fig. $5 \mathrm{f}$ for daily average curves). The increase in $L \downarrow$ is expressed between evening and early morning and is a direct result of higher mixing ratios at $2 \mathrm{~m}$ in INT (not shown). The change in radiative forcing in INT translates into less heat extraction from the surface layer, through a reduced nocturnal QS, and, in turn, into the near-surface temperature difference. Note that the near-surface air temperature evolution simulated in INT may represent an improvement, as Mölg et al. (2012b) found that WRF + Noah LSM can produce an excessively large diurnal cycle as a result of a nighttime cold bias at $2 \mathrm{~m}$ compared with AWS measurements on Kilimanjaro. Interactive coupling also results in a reduction of mean incoming short-wave radiation $\left(-9.0 \mathrm{~W} \mathrm{~m}^{-2}\right)$ and, as previously mentioned, a mean increase in incoming long-wave radiation (2.4), changes that arise from alterations to atmospheric clouds and moisture (see Fig. 6). Basin-scale daily-mean differences in the other forcing variables for the CMB model are negligible.

The atmospheric changes induced by including feedbacks from the CMB model are generally small in magnitude and limited in vertical extent, but still appreciable. Air temperature and mixing ratio anomalies are generally confined to the lowest 10 model levels, which correspond to the layer between a mean surface pressure of $543 \mathrm{hPa}$ and the level of $450 \mathrm{hPa}$ (Fig. 6a). Vertical changes in the mean cloud cover fraction are variable, with the greatest differences present

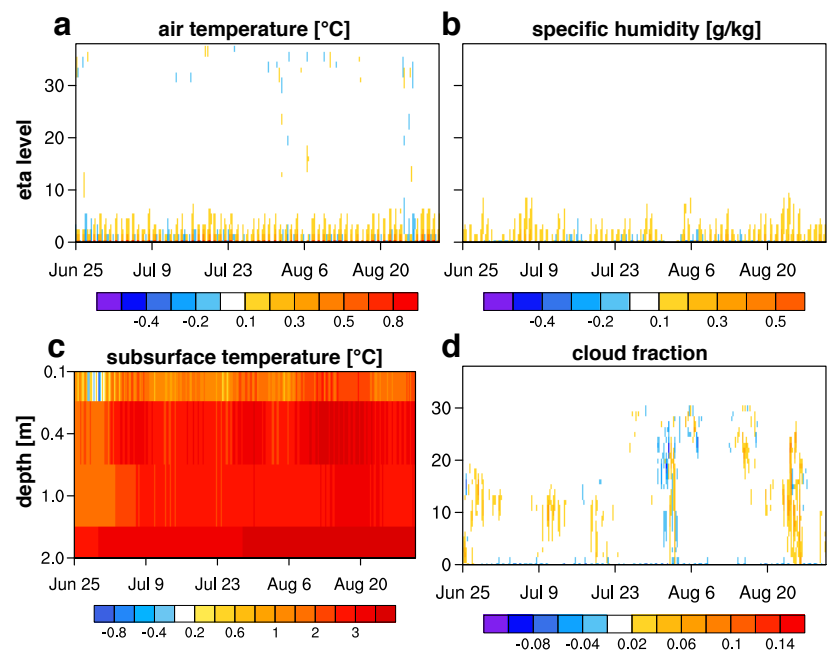

Fig. 6. Vertical and subsurface distribution of the influence of interactive coupling over glaciated areas illustrated by hourly time series of the change (INT-OFF) in area-averaged (a) air temperature,(b) specific humidity, (c) subsurface temperature, and (d) cloud fraction.

near the levels of $375(\eta=12-14)$ and $125 \mathrm{hPa}(\eta=26-29$; Fig. 6d). However, interactive coupling has a strong warming influence on the subsurface temperature distribution (on average, $+2.6 \mathrm{~K}$; Fig. $6 \mathrm{c}$ ), as a result of (1) the inclusion of the energy flux from penetrating solar radiation, and (2) the method for updating deep soil temperature $\left(T_{\mathrm{ds}}\right)$, which is defined at a depth of $3 \mathrm{~m}$. With regard to the latter point, $T_{\mathrm{ds}}$ in INT is taken from the CMB model subsurface scheme, which resolves the column to a depth of $9 \mathrm{~m}$ but is constrained by a lower boundary temperature of $268.6 \mathrm{~K}$ in this study. In contrast, the Noah LSM updates $T_{\mathrm{ds}}$ using a weighted combination of the annual mean $T_{\mathrm{sfc}}$ of the previous year and of the last 150 days as the data become available, with no lower threshold imposed. The resulting minimum values for $T_{\mathrm{sfc}}$ in the CMB model and Noah LSM are $\sim 245$ and $224 \mathrm{~K}$, respectively.

The non-negligible influence of interactive coupling on the near-surface meteorological forcing data translates primarily into reduced ablation of snow and ice in INT (Fig. 7a and b). Area-averaged modelled surface height lowering is smaller and total mass balance is less negative in INT, with a mean reduction in ablation over the Karakoram basin of $0.1 \mathrm{~m}$ w.e. $(-6.0 \%)$, to a cumulative value of $-1.5 \mathrm{~m}$ w.e. by $31 \mathrm{Au}-$ gust. The difference in the total mass balance arises despite higher $T_{\text {sfc }}$ in INT (Fig. 7c). The inclusion of additional processes, such as the refreezing of meltwater, and the different method of subsurface temperature calculation both contribute to higher $T_{\text {sfc }}$ in both INT and OFF compared with the Noah LSM.

The vertical balance profile (VBP) on 31 August 2004, is shown in Fig. 8a, with areas of negative (positive) balance modelled below (above) $\sim 5875 \mathrm{~m}$. The altitudinal 

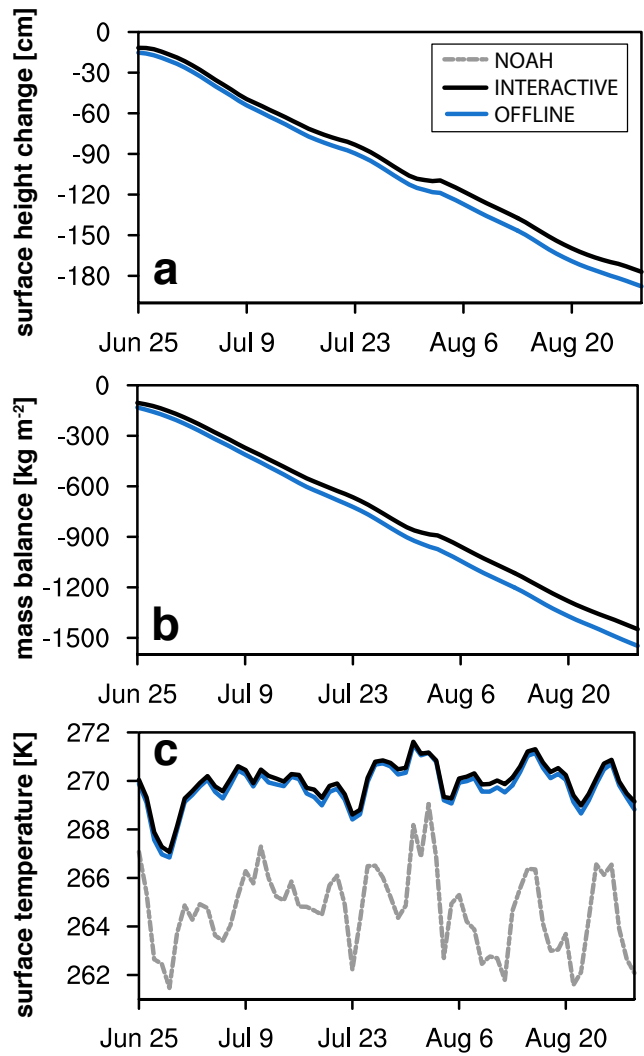

Fig. 7. Daily basin-scale averages of (a) accumulated surface height change, (b) accumulated total mass balance, and (c) surface temperature. Black (blue) curves display data from the interactive (offline) simulation. For reference, surface temperature simulated by the Noah LSM is the dashed grey curve in (c).

distribution is characterized by a shallowing of the VBP above $\sim 5000 \mathrm{~m}$, associated with (1) an increase in the positive vertical gradient of the fraction of solid precipitation that contributes positively to CMB (Fig. 8c), and (2) cooling of mean surface temperature with height to below the melting point (cf. Fig. 2a). Above $5875 \mathrm{~m}$, the VBP profile again steepens as a result of large increases in accumulated, solid precipitation. Below $5875 \mathrm{~m}$, INT produces less ablation (on average, $117.7 \mathrm{~mm}$ w.e.), while above this level it simulates a mean increase in accumulation (13.4) in part due to small increases in both accumulated precipitation and its frozen fraction (cf. Fig. $8 \mathrm{~b}$ and c). Averaged over the whole period, the equilibrium line altitudes are 5469 and $5536 \mathrm{~m}$ in INT and OFF, respectively, which exceed the annual and generalized estimate of $4500 \mathrm{~m}$ by Hewitt (2005) and of 4200-4800 m by Young and Hewitt (1993), because we only simulate the ablation season.

Figure 9 presents the surface fluxes of energy and mass from the interactive simulation. On average, the main energy sources are incoming radiation, $S \downarrow\left(374.3 \mathrm{~W} \mathrm{~m}^{-2}\right)$ and $L \downarrow$ (220.4), with smaller contributions from QS (9.5) and QC (8.1; Fig. 9a). The main energy sinks are outgoing
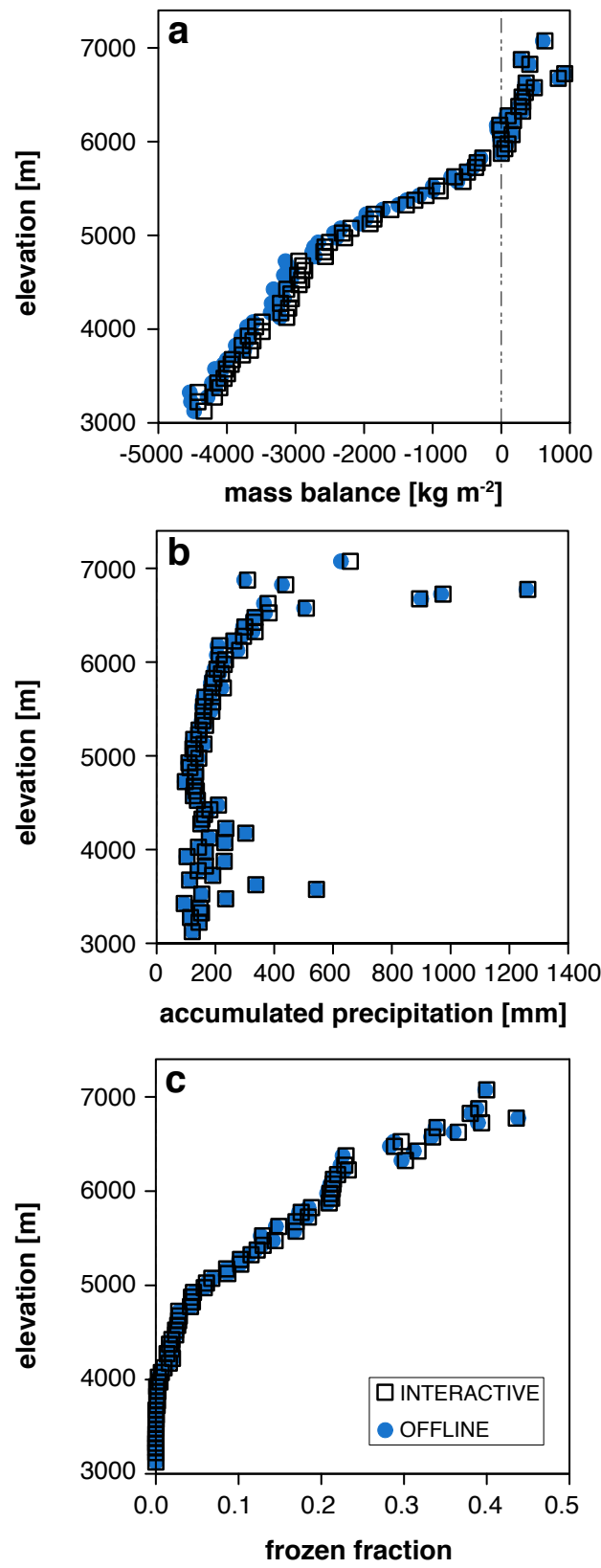

Fig. 8. (a) The vertical mass balance profile of the Karakoram basin at the end of the simulation. The altitudinal dependence of (b) total accumulated precipitation, and (c) mean frozen fraction, averaged over the simulation. Data are area-averaged in $50 \mathrm{~m}$ elevation bins.

$L \uparrow(-306.1)$ and reflected $S \uparrow(-186.4)$, followed by QM $(-74.0)$, QPS $(-32.1)$, and QL $(-13.9)$. Mass gains are, in general, dominated by refreeze $\left(1.0 \mathrm{~kg} \mathrm{~m}^{-2}\right)$ and solid precipitation $(0.9$; Fig. 9 b), while mass loss is primarily through surface $(-19.1)$ and subsurface $(-3.2)$ melt. Figure 9 also illustrates the main advantage of the coupled model: it elucidates the important physical processes behind a mass change signal that results from atmospheric forcing. For example, 

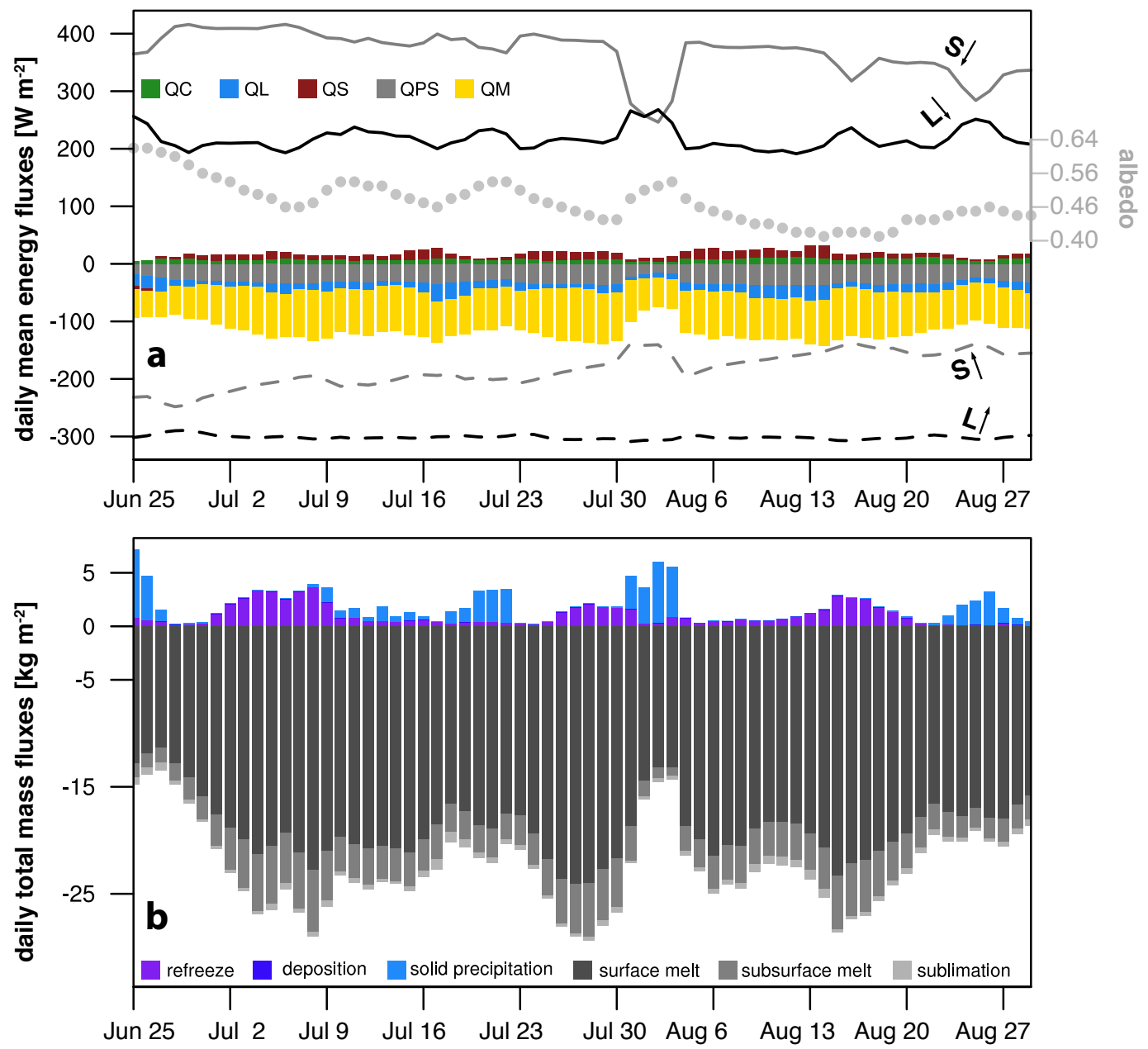

Fig. 9. From the interactive WRF-CMB simulation: daily (a) mean surface energy balance components (left y-axis; see Eq. 1 for explanation of symbols) and albedo values (grey right y-axis), and (b) sums of mass fluxes. The radiation variables are shown in (a) as solid (directed downward) and dashed (upward) lines, albedo as grey dots, and the other surface energy fluxes as bars. The heat flux from precipitation (QPRC) is negligible and not shown. Values are averaged over glaciated grid cells only.

the snowfall event that occurs at the beginning of August (cf. solid precipitation bars in Fig. 9b) is clearly associated with (1) a reduction in $S \downarrow$ and an increase in $L \downarrow$, (2) a spike in both surface albedo and thus $S \uparrow$, and (3) a reduction in absorbed short-wave radiation that translates into reduced energy for surface and subsurface melt. Furthermore, changes in glacier surface conditions have a noticeable feedback on the atmosphere during and after the snowfall event (cf. e.g. $S \downarrow$ in Fig. 5e or cloud fraction changes in Fig. 6d).

Interactive coupling has the strongest influence on the net short-wave and ground heat fluxes in the atmospheric model (Fig. 10a). The average QG in INT $\left(-23.7 \mathrm{~W} \mathrm{~m}^{-2}\right)$ greatly exceeds that simulated by the Noah LSM alone $(-0.5)$, due to (1) the inclusion of penetrating short-wave radiation, which always represents an energy sink at the surface, and (2) higher surface temperatures, which result in a stronger (more negative) flux downward to the subsurface. Mean absorbed short-wave radiation is also much larger in INT (184.8 vs. 107.9), as a result of lower average surface albedo (0.49 vs. 0.71; see Fig. 2c) over the simulation period. Smaller changes in the turbulent heat fluxes reflect in part different treatments of surface roughness, which is a spatially and temporally varying parameter in WRF-CMB that ranges between 0.8 and $2.6 \mathrm{~mm}$ as a function of snow age and generally exceeds the constant value of $1 \mathrm{~mm}$ specified by the Noah LSM for snow/ice surfaces.

In the CMB model, interactive coupling induces the largest magnitude change in the net short-wave $(-3.3 \%$, ) and longwave $(+1.8 \%$, ) radiative fluxes, as a result of the changes to $S \downarrow$ and $L \downarrow$ in the atmospheric model discussed previously. The CMB model fluxes of QL and QPS decrease (become less negative) on average in INT by $8.9 \%$ and $3.5 \%$, respectively (Fig. 10b). In addition, QC and QS are reduced by $9.0 \%$ and $5.0 \%$, respectively. The reduction in QPS is associated with less snow-cover-free glacier area in INT, which reduces the subsurface absorption of short-wave radiation 

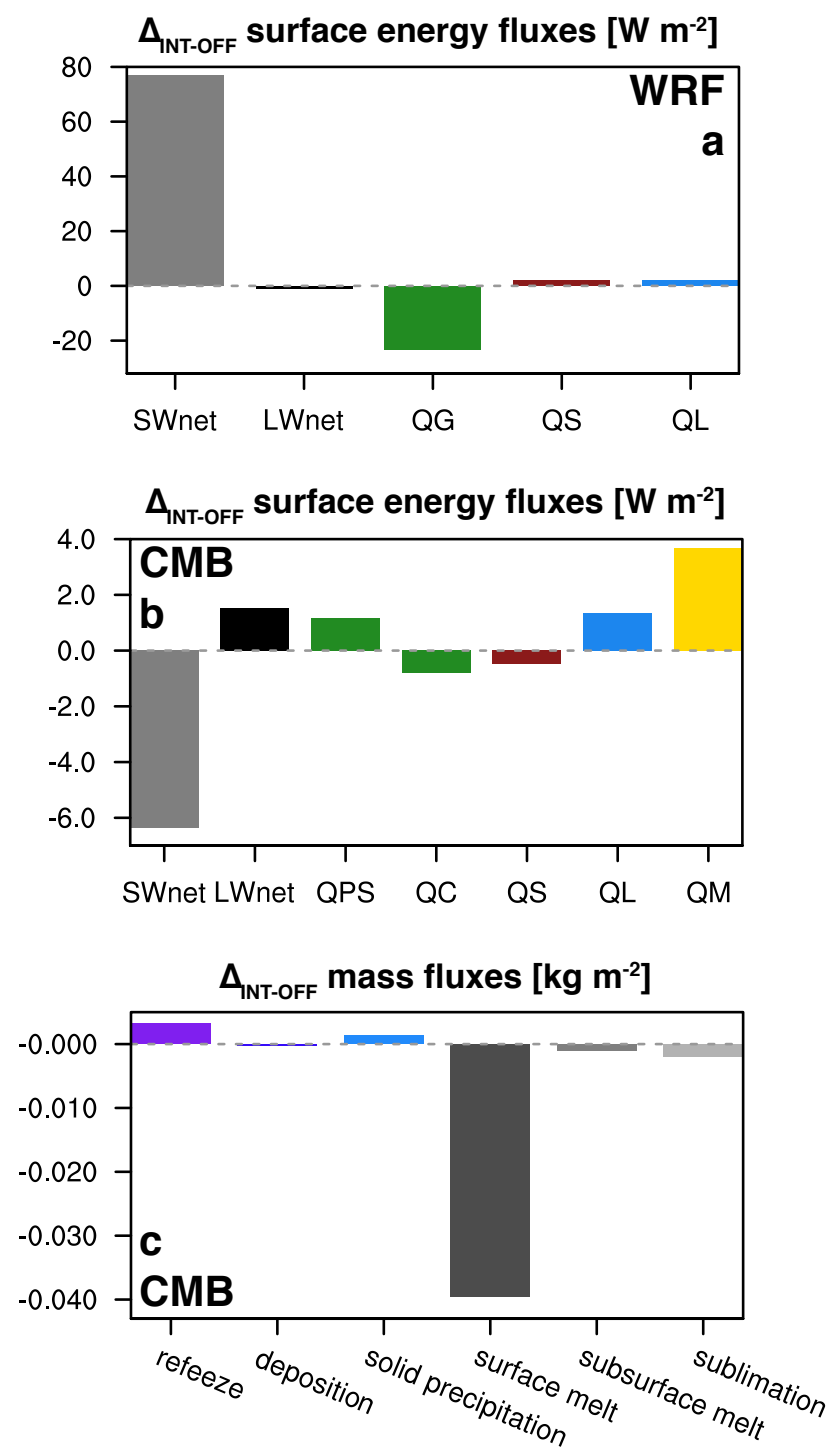

Fig. 10. Area-averaged mean difference (INT - OFF) over the simulation period and over glaciated grid cells of (a) the main components of the WRF surface energy budget, (b) the MB model energy fluxes, and (c) the MB model mass fluxes. Symbols in (a) represent, from left to right, net short- and long-wave radiation, ground heat flux, and turbulent fluxes of sensible and latent heat. Note that the sign convention for the turbulent fluxes in (a) is opposite to (b). Symbols in (b) are discussed in Sect. 2.2

(Mölg et al., 2008). The reduction in the turbulent heat fluxes appears to stem from reduced $10 \mathrm{~m}$ wind speeds $(-0.2$ to $4.3 \mathrm{~m} \mathrm{~s}^{-1}$ ), due to the surface roughness changes discussed above. The changes also occur despite (1) a weaker correction for atmospheric stability on average, according to a modified version of the Monin-Obukhov stability function (Eq. 12 in Braithwaite, 1995); and (2) stronger mean gradients in vapor pressure $(\Delta \mathrm{VP} ;-1.2$ in INT vs. $-0.7 \mathrm{hPa}$ in OFF) and temperature $(\Delta T ; 1.8$ vs. $1.2 \mathrm{~K})$ between the nearsurface and lower boundary.
The net result is a decrease of $4.8 \%$ in the average energy available for surface melt, QM, and less negative mass balance over the INT simulation (cf. Fig. 7b). The difference is primarily reflected in a reduction in surface melt $(-5.8 \%$; Fig. 10c), and is compounded by increases in both refreezing in the snowpack and the formation of superimposed ice $(8.5 \%$ combined) as well as by greater solid precipitation $(4.0 \%)$. In general, mass exchanges between the glacier surface and the overlying boundary layer are smaller in INT, with the weakening in QL resulting in less sublimation (particularly at night) and deposition (at all times).

\subsection{Remarks and perspectives for future research}

The explicit approach to modelling alpine glacier climatic mass balance using WRF first demonstrated by Mölg and Kaser (2011) has been applied in offline mode for simulations of small glaciers (Mölg and Kaser, 2011; Mölg et al., 2012a,b) and has yielded important insights into the physical processes and the atmospheric forcing underlying mass fluctuations. However, here we demonstrate that feedbacks due to CMB processes are evident for the heavily-glaciated Karakoram region. The basin-scale influence of interactive coupling on the atmospheric forcing data, while moderate, acts to reduce the energy available for surface melt and, in concert with both reduced mass exchanges between the surface and boundary layer and increased refreezing, reduces modelled ablation during the summer of 2004. Furthermore, we demonstrate that the inclusion of additional real processes such as CMB feedbacks renders WRF-CMB capable of simulating observed magnitudes of CMB.

To the best of our knowledge, only one previous study, that of Kotlarski et al. (2010b), has performed interactive and distributed simulations of alpine glacier mass balance, achieved by introducing a subgrid-scale parameterization for glaciers and their areal changes into a regional climate model configured with a relatively coarse spatial resolution of $\sim 18 \mathrm{~km}$. However, their implicit treatment "pools" the glaciers located in a grid cell into one ice mass at a fixed altitude and with a uniform snow depth. Furthermore, they quantify the effect of two-way coupling by comparing their interactive simulation with a control run that contains no glaciers (i.e. snow and ice surfaces are compared with bare soil or vegetationcovered surfaces), thus obscuring the exact role of feedbacks. Therefore, this paper presents the first assessment of the importance and strength of interactions between alpine glaciers and the atmosphere on explicit simulations of CMB.

We have shown results for only a short study period, of one ablation season, to evaluate the novel approach and its performance against the available measurements. The Karakoram, and the Himalayan region in general, are very data-sparse (e.g. Bolch et al., 2012), due to the expense and logistics of field surveys in this remote region. The model captures the magnitude of the 53 stake measurements of Mihalcea et al. (2006), and simulating the ablation season likely represents 
the greatest test for some of the simplifying assumptions employed, such as zero debris cover. However, a longer application is needed to assess the year-long and inter-annual influence of interactive coupling, as well as the long-term performance of the atmospheric model under the climatesimulation forcing strategy we employ (i.e. with no nudging or model re-initialization; e.g. Maussion et al., 2011). Simulations of glacier mass balance are also inherently sensitive to the modeled solid precipitation (Mölg and Kaser, 2011), which is influenced in our study by the choice of microphysics scheme. Furthermore, the optimal choice of diffusion scheme, its strength, and its influence on simulated precipitation and therefore glacier CMB are beyond the scope of this paper and have not been investigated fully for our area of interest and model configuration. The simulation of near-surface meteorological fields by WRF over glacier surfaces has been found to be relatively insensitive to the choice of physical parameterizations (Claremar et al., 2012); however, the extent to which modelled CMB is dependent on the model physics, the choice of numerics, and the spatial resolution of the finest domain represents an important uncertainty that will be explored in a future study.

The mean proportion of debris covered-area on Karakoram glaciers is estimated to be 18-22\% (Scherler et al., 2011; Hewitt, 2011), which is higher than the pan-Himalayan average of $\sim 10 \%$ (Bolch et al., 2012). Specific to the Baltoro glacier, Mayer et al. (2006) estimate that $\sim 38 \%$ of the total glacier area is debris covered. The presence of debris above a threshold, or "critical thickness", of $\sim 2 \mathrm{~cm}$ has been shown, empirically and through surface energy balance modelling, to reduce glacier ablation as a result of its insulating effect (e.g. Østrem, 1959; Kayastha et al., 2000; Nicholson and Benn, 2006; Reid et al., 2012). The range of mean debris thicknesses at the stake sites is $2.0-18.0 \mathrm{~cm}$ (Table 4), suggesting that on the whole insulation effects should dominate over the lowering of surface albedo except at the sites L2 and L3 where debris thickness is approximately equal to the critical value. Indeed modelled ablation closely matches the measured rate at these two sites and elsewhere is overestimated by WRF-CMB (Fig. 4c), physically consistent with the exclusion of debris in this study. This interpretation is supported by the first distributed ablation modelling study for debris-covered ice, that of Reid et al. (2012), which found reduced sub-debris ablation when depth exceeded $2 \mathrm{~cm}$. However, it is noteworthy that geodetic estimates of early $21 \mathrm{st}$ century elevation changes in the Karakoram (Gardelle et al., 2012; Kääb et al., 2012) do not show a difference between clean and debris-covered ice.

Given the similarity of the underlying surface types in INT (snow/ice) and OFF (snow) influencing the atmospheric forcing data, the difference in simulated CMB for the clean glacier simulations is relatively small. From the results presented here, it could be expected that the inclusion of feedbacks is not essential for small glaciers or less glaciated basins. However, we would expect the interactive inclusion of the CMB model to have a larger influence for glaciers with significant debris cover, as its presence alters surface temperature and moisture properties and thus turbulent exchanges with the surface boundary layer (e.g. Takeuchi et al., 2000). To assess the role of feedbacks for debris-covered glaciers and to allow the WRF-CMB modelling system to provide long-term, accurate simulations in the Karakoram, including the effects of debris cover on surface conditions and glacier ablation represents important future work. Treating debris cover in distributed mass balance modelling is also becoming more important in light of observations of increasing debris-covered area in many regions (e.g. Stokes et al., 2007; Bhambri et al., 2011). Another process that is thought to be important for Karakoram glaciers is accumulation via snow and ice avalanching (e.g. Hewitt, 2011), which may be useful to parameterize. Finally, dynamical ice flow changes have been shown to be important when quantifying the response of Himalayan glaciers to climate fluctuations on multiannual timescales (e.g. Scherler et al., 2011; Gardelle et al., 2012; Kääb et al., 2012; Azam et al., 2012).

\section{Conclusion}

CMB feedbacks have been introduced into a new, multi-scale modelling approach for explicitly resolving the surface and climatic mass balance processes of alpine glaciers, and this technique has been extended to the regional scale. Although validation data is sparse, the model captures the magnitude of available in situ measurements, with improvements arising from including feedbacks from the CMB model to WRF. Furthermore, discrepancies between observed and simulated ablation can be attributed to physical processes neglected as simplifying assumptions, particularly debris cover effects.

Both components of WRF-CMB are based on physical principles, with no statistical downscaling at their interface. The direct linkage increases the applicability of this approach for the simulation of the past- and future-climate response of glaciers, since the modelling system produces a physicallyconsistent response to changes in external forcing. Incorporation of the CMB model also increases the number of physical processes important for glaciers represented in the atmospheric model, and provides a consistent calculation of surface energy and mass fluxes, since changes in glacier surface conditions are permitted to influence the atmospheric drivers. Perhaps the most important advantage, however, is that WRF-CMB permits direct causal attribution of glacier mass changes to both physical processes and the main atmospheric drivers. With further development, the model has the potential to bridge the data gap in the Karakoram and shed light on the role of climate forcing in the anomalous behaviour of glaciers in this region.

The offline approach to simulations of CMB, as well as the simplified representation of glaciers in regional atmospheric models, essentially treats either the atmosphere or 
alpine glaciers simply as a boundary condition. We suggest that this unified, explicit approach should be increasingly adopted in future studies, particularly for heavily glaciated regions.

Acknowledgements. E. Collier was supported by a Natural Sciences and Engineering Research Council of Canada (NSERC) CGS-D award, a NSERC Michael Smith Foreign Study Scholarship, and an Alberta Ingenuity Graduate Student Scholarship. T. Mölg was supported by the Alexander von Humboldt Foundation. F. Maussion and D. Scherer acknowledge support from the German Research Foundation (DFG) Priority Programme 1372 under the code SCHE 750/4-3, and the German Federal Ministry of Education and Research (BMBF) Programme CAME under the code 03G0804A. A.B.G. Bush acknowledges support from NSERC and from the Canadian Institute for Advanced Research. The supercomputing resources for this study were provided by Compute/Calcul Canada. The authors thank Ev-K2-CNR for providing the meteorological data from the Baltoro glacier, together with the University of Milan for supporting the field work. They would also like to thank V. Radic and two anonymous reviewers for their constructive comments.

Edited by: V. Radic

\section{References}

Azam, M. F., Wagnon, P., Ramanathan, A., Vincent, C., Sharma, P., Arnaud, Y., Linda, A., Pottakkal, J. G., Chevallier, P., Singh, V. B., and Berthier, E.: From balance to imbalance: a shift in the dynamic behaviour of Chhota Shigri glacier, western Himalaya, India, J. Glaciol., 58, 315-324, 2012.

Bhambri, R., Bolch, T., Chaujar, R. K., and Kulshreshtha, S. C.: Glacier changes in the Garhwal Himalaya, India, from 1968 to 2006 based on remote sensing, J. Glaciol., 57, 543-556, 2011.

Bolch, T., Kulkarni, A., Kääb, A., Huggel, C., Paul, F., Cogley, J. G., Frey, H., Kargel, J. S., Fujita, K., Scheel, M., Bajracharya, S., and Stoffel, M.: The state and fate of Himalayan glaciers, Science, 336, 310-314, 2012.

Braithwaite, R. J.: Aerodynamic stability and turbulent sensibleheat flux over a melting ice surface, the Greenland ice sheet, J. Glaciol., 41, 562-571, 1995.

Brodzik, M. J., Armstrong, R., and Savoie, M.: Global EASE-Grid 8-day Blended SSM/I and MODIS Snow Cover, National Snow and Ice Data Center, Boulder, Colorado, USA, Digital media, 2007.

Bryan, G. H., Wyngaard, J. C., and Fritsch, J.: Resolution requirements for simulations of deep moist convection, Mon. Weather Rev., 131, 2394-2416, 2003.

Chen, F. and Dudhia, J.: Coupling an advanced land surfacehydrology model with the Penn State - NCAR MM5 modelling system. Part I: Model implementation and sensitivity, Mon. Weather Rev., 129, 569-585, 2001.

Claremar, B., Obleitner, F., Reijmer, C., Pohjola, V., Waxegård, A., Karner, F., and Rutgersson, A.: Applying a mesoscale atmospheric model to Svalbard glaciers, Adv. Meteorol., 2012, 321649, doi:10.1155/2012/321649, 2012.
Cogley, J. G.: Present and future states of Himalaya and Karakoram glaciers, Ann. Glaciol., 52, 69-73, 2011.

Cogley, J. G., Hock, R., Rasmussen, L. A., Arendt, A. A., Bauder, A., Braithwaite, R. J., Jansson, P., Kaser, G., Müller, M., Nicholson, L., and Zemp, M.: Glossary of Glacier Mass Balance and Related Terms, IHP-VII Technical Documents in Hydrology No. 86, IACS Contribution No. 2, UNESCO-IHP, Paris, 2011.

Craig, G. C. and Dörnback, A.: Entrainment in cumulus clouds: What resolution is cloud-resolving?, J. Atmos. Sci., 65, 39783988, 2008.

Dee, D. P., Uppala, S. M., Simmons, A. J., Berrisford, P., Poli, P., Kobayashi, S., Andrae, U., Balmaseda, M. A., Balsamo, G., Bauer, P., Bechtold, P., Beljaars, A. C. M., van de Berg, L., Bidlot, J., Bormann, N., Delsol, C., Dragani, R., Fuentes, M., Geer, A. J., Haimberger, L., Healy, S. B., Hersbach, H., Hlm, E. V., Isaksen, L., Kållberg, P., Köhler, M., Matricardi, M., McNally, A. P., Monge-Sanz, B. M., Morcrette, J.-J., Park, B.K., Peubey, C., de Rosnay, P., Tavolato, C., Thpaut, J.-N., and Vitart, F.: The ERA-Interim reanalysis: configuration and performance of the data assimilation system, Q. J. Roy. Meteorol. Soc., 137, 553-597, 2011.

Frey, H., Paul, F., and Strozzi, T.: Compilation of a glacier inventory for the western Himalayas from satellite data: methods, challenges, and results, Remote Sens. Environ., 124, 832-843, 2012.

Gardelle, J., Berthier, E., and Arnaud, Y.: Slight mass gain of Karakoram glaciers in the early twenty-first century, Nat. Geosci., 5, 322-325, 2012.

Gardner, A. S., Sharp, M. J., Koerner, R. M., Labine, C., Boon, S., Marshal, S. J., Burgess, D. O., and Lewis, E.: Near-surface temperature lapse rates over Arctic glaciers and their implications for temperature downscaling, J. Climate, 22, 4281-4298, 2009.

Hewitt, K.: The Karakoram anomaly? Glacier expansion and the "elevation effect" Karakoram Himalaya, Mt. Res. Dev., 25, 332340, 2005.

Hewitt, K.: Glacier change, concentration, and elevation effects in the Karakoram Himalaya, Upper Indus Basin, Mt. Res. Dev., 31, 188-200, 2011.

ICIMOD (International Centre for Integrated Mountain Development): Inventory of glaciers, glacial lakes and identification of potential glacial lake outburst floods (GLOFs), affected by global warming in the Mountains of Himalayan Region, Kathmandu, DVD-ROM, 2007.

Jiménez, P. A., Dudhia, J., González-Rouco, J. F., Navarro, J., Montávez, J. P., and García-Bustamante, E.: A revised scheme for the WRF surface layer formulation, Mon. Weather Rev., 140, 898-918, 2012.

Kääb, A., Berthier, E., Nuth, C., Gardelle, J., and Arnaud, Y.: Contrasting patterns of early twenty-first-century glacier mass change in the Himalayas, Nature, 488, 495-498, 2012.

Kayastha, R. B., Takeuchi, Y., Nakawo, M., and Ageta, Y.: Practical prediction of ice melting beneath various thickness of debris cover on Khumbu Glacier, Nepal using a positive degree- day factor, Symposium at Seattle 2000 - Debris-Covered Glaciers, IAHS Publ., 264, 71-81, 2000.

Kotlarski, S., Paul, F., and Jacob, D.: Forcing a distributed glacier mass balance model with the regional climate model REMO. Part I: Climate model evaluation, J. Climate, 23, 1589-1606, 2010a.

Kotlarski, S., Jacob, D., Podzum, R., and Paul, F.: Representing glaciers in a regional climate model, Clim. Dynam., 34, 27-46, 
2010b.

Knievel, J. C., Bryan, G. H., and Hacker, J. P.: Explicit numerical diffusion in the WRF model, Mon. Weather Rev., 135, 38083824, 2007.

Livneh, B., Xia, Y., Mitchell, K. E., Ek, M. B., and Lettenmaier, D. P.: Noah LSM snow model diagnostics and enhancements, J. Hydrometeorol., 11, 721-738, 2009.

Machguth, H., Paul, F., Kotlarski, S., and Hoelzle, M.: Calculating distributed glacier mass balance for the Swiss Alps from regional climate model output: a methodical description and interpretation of the results, J. Geophys. Res., 114, D19106, doi:10.1029/2009JD011775, 2009.

Marshall, S. J., Sharp, M. J., Burgess, D. O., and Anslow, F. S.: Surface temperature lapse rate variability on the Prince of Wales Iceeld, Ellesmere Island, Canada: implications for regional-scale downscaling of temperature, Int. J. Climatol., 27, 385-398, 2007.

Maussion, F., Scherer, D., Finkelnburg, R., Richters, J., Yang, W., and Yao, T.: WRF simulation of a precipitation event over the Tibetan Plateau, China - an assessment using remote sensing and ground observations, Hydrol. Earth Syst. Sci., 15, 1795-1817, doi:10.5194/hess-15-1795-2011, 2011.

Mayer, C., Lambrecht, A., Belo, M., Smiraglia, C., and Diolaiuti, G.: Glaciological characteristics of the ablation zone of Baltoro glacier, Karakoram, Pakistan, Ann. Glaciol., 43, 123131, 2006.

Mihalcea, C., Mayer, C., Diolaiuti, G., Smiraglia, C., and Tartari, G.: Ablation conditions on the debris covered part of Baltoro Glacier, Karakoram, Ann. Glaciol., 43, 292-300, 2006.

Mihalcea, C., Mayer, C., Diolaiuti, G., DAgata, C., Smiraglia, C., Lambrecht, A., Vuillermoz, E., and Tartari, G.: Spatial distribution of debris thickness and melting from remote-sensing and meteorological data, at debris-covered Baltoro glacier, Karakoram, Pakistan, Ann. Glaciol., 48, 49-57, 2008.

Molinari, J. and Dudek, M.: Parameterization of convective precipitation in mesoscale numerical-models - a critical-review, Mon. Weather Rev., 120, 326-344, 1992.

Mölg, T. and Kaser, G.: A new approach to resolving climatecryosphere relations: downscaling climate dynamics to glacierscale mass and energy balance without statistical scale linking, J. Geophys. Res., 116, D16101, doi:10.1029/2011JD015669, 2011.

Mölg, T., Cullen, N. J., Hardy, D. R., Kaser, G., and Klok, E. J.: Mass balance of a slope glacier on Kilimanjaro and its sensitivity to climate, Int. J. Climatol., 28, 881-892, 2008.

Mölg, T., Cullen, N. J., Hardy, D. R., Winkler, M., and Kaser, G.: Quantifying climate change in the tropical midtroposphere over East Africa from glacier shrinkage on Kilimanjaro, J. Climate, 22, 4162-4181, 2009.

Mölg, T., Maussion, F., Yang, W., and Scherer, D.: The footprint of Asian monsoon dynamics in the mass and energy balance of a Tibetan glacier, The Cryosphere, 6, 1445-1461, doi:10.5194/tc6-1445-2012, 2012a.

Mölg, T., Grohauser, M., Hemp, A., Hofer, M., and Marzeion, B.: Limited forcing of glacier loss through land-cover change on Kilimanjaro, Nat. Clim. Change, 2, 254-258, 2012b.

Nicholson, L. and Benn, D.: Calculateing ice melt beneath a debris layer using meteorological data, J. Glaciol., 52, 463-470, 2006.

Niu, G.-Y., Yang, Z.-L., Mitchell, K. E., Chen, F., Ek, M. B., Barlage, M., Kumar, A., Manning, K., Niyogi, D., Rosero, E., Tewari, M., and Youlong, X.: The community Noah land surface model with multiparameterization options (Noah-MP): 1. Model description and evaluation with local-scale measurements, J. Geophys. Res., 116, D12109, doi:10.1029/2010JD015139, 2011.

Oerlemans, J. and Knap, W. H.: A 1 year record of global radiation and albedo in the ablation zone of Morteratschgletscher, Switzerland, J. Glaciol., 44, 231-238, 1998.

Østrem, G.: Ice melting under a thin layer of moraine, and the existence of ice cores in moraine ridges, Geogr. Ann., 41, 228-230, 1959.

Paul, F. and Kotlarski, S.: Forcing a distributed glacier mass balance model with the regional climate model REMO. Part II: Downscaling strategy and results for two Swiss glaciers, J. Climate, 23, 1607-1620, 2010.

Petch, J. C.: Sensitivity study of developing convection in a cloudresolving model, Q. J. Roy. Meteorol. Soc., 132, 345-358, 2006.

Petersen, L. and Pellicciotti, F.: Spatial and temporal variability of air temperature on a melting glacier: atmospheric controls, extrapolation methods and their effect on melt modeling, Juncal Norte Glacier, Chile, J. Geophys. Res., 116, D23109, doi:10.1029/2011JD015842, 2011.

Pritchard, M. S., Bush, A. B. G., and Marshall, S. J.: Neglecting ice-atmosphere interactions underestimates ice sheet melt in millennial-scale deglaciation simulations, Geophys. Res. Lett., 35, L01503, doi:10.1029/2007GL031738, 2008.

Radić, V. and Hock, R.: Regionally differentiated contribution of mountain glaciers and ice caps to future sea-level rise, Nat. Geosci., 4, 91-94, 2011.

Reid, T. D., Carenzo, M., Pellicciotti, F., and Brock, B. W.: Including debris cover effects in a distributed model of glacier ablation, J. Geophys. Res., 117, D18105, doi:10.1029/2012JD017795, 2012.

Ridley, J. K., Huybrechts, P., Gregory, J. M., and Lowe, J. A.: Elimination of the Greenland ice sheet in a high $\mathrm{CO}_{2}$ climate, J. Climate, 18, 3409-3427, 2005.

Scherler, D., Bookhagen, B., and Strecker, M. R.: Spatially variable response of Himalayan glaciers to climate change affected by debris cover, Nat. Geosci., 4, 156-159, 2011.

Shi, Y., Liu, C., and Kang, E.: The glacier inventory of China, Ann. Glaciol., 50, 1-4, 2009.

Skamarock, W. C. and Klemp, J. B.: A time-split nonhydrostatic atmospheric model for weather research and forecasting applications, J. Comput. Phys., 227, 3465-3485, 2008.

Stokes, C. R., Popovnin, V., Aleynikov, A., Gurney, S. D., and Shahgedanova, M.: Recent glacier retreat in the Caucasus Mountains, Russia, and associated increase in supraglacial debris cover and supra-/proglacial lake development, Ann. Glaciol., 46, 195203, 2007.

Stroeve, J. C., Box, J. E., and Haran, T.: Evaluation of the MODIS (MOD10A1) daily snow albedo product over the Greenland ice sheet, Remote Sens. Environ., 105, 155-171, 2006.

Takeuchi, Y., Kayastha, R. B., and Nakawo, M.: Characteristics of ablation and heat balance in debris-free and debris-covered areas on Khumbu glacier, Nepal Himalayas, in the pre-monsoon season, in: Debris-covered glaciers, IAHS Publ., 264, 53-61, 2000.

van Pelt, W. J. J., Oerlemans, J., Reijmer, C. H., Pohjola, V. A., Pettersson, R., and van Angelen, J. H.: Simulating melt, runoff and refreezing on Nordenskiöldbreen, Svalbard, using a coupled snow and energy balance model, The Cryosphere, 6, 641-659, doi:10.5194/tc-6-641-2012, 2012. 
Weisman, M. L., Skamarock, W. C., and Klemp, J. B.: The resolution dependence of explicitly modeled convective systems, Mon. Weather Rev., 125, 527-548, 1997.

Yao, T.: Map of the Glaciers and Lakes on the Tibetan Plateau and Adjoining Regions, Xian Cartographic Publishing House, Xian, China, 2007.
Young, G. J. and Hewitt, K.: Glaciohydrological features of the Karakoram Himalaya: measurement possibilities and constraints, in: Proceedings of the Kathmandu Symposium - Snow and Glacier Hydrology, IAHS Publ., 218, 273-283, 1993. 